\title{
REVIEW
}

\section{Analysis of Communication Strategies in the New Media Age}

\section{Qi Wang* Meili Liang Qi Zhao}

School of Management, Shandong University of Technology, Zibo, Shandong, 255000, China

\begin{tabular}{|c|c|}
\hline ARTICLE INFO & ABSTRACT \\
\hline Article history & This paper explores how enterprises respond to changes in consumers and \\
\hline Received: 6 June 2019 & make corresponding adjustments in communication strategies in the new \\
\hline Revised: 1 July 2019 & media age. The cases of Jiang Xiaobai and Netease Cloud are selected for \\
\hline Accepted: 9 October 2019 & $\begin{array}{l}\text { the present analysis, providing suggestions for communication strategies } \\
\text { in the new media age. }\end{array}$ \\
\hline
\end{tabular}

Published Online: 16 October 2019

\section{Keywords:}

New media age

Communication

Public relations

Advertising

\section{Background of the New Media Age}

$\mathrm{T}$ The emergence of new media has promoted the change of netizens' habits of surfing the Internet, entertainment, social intercourse and consumption. It has changed consumers' consumption patterns and demand patterns. Corporate communication strategies should also be changed accordingly. New media covers all forms of digital media, including digital traditional media, network media, mobile media, digital television, digital newspapers and magazines, etc. It is a relatively tradition- al concept of media communication. In the new media age, enterprises use digital technology, network technology and mobile technology to provide information and entertainment services to consumers through the Internet, satellite and other channels, as well as computers, mobile phones and other terminals. ${ }^{[1]}$

The "new" in the new media age is mainly embodied in the innovation of communication technology, communication form and consumer concept. Firstly, the media that enterprises can adopt are richer, faster and more influ-

*Corresponding Author:

Qi Wang,

Female, a native of Zibo in Shandong Province, associate professor;

Correspondence address: School of Management, Shandong University of Technology, No. 88, Gongqingtuan West Road, Zhangdian District, Zibo, Shandong, 255000, China;

E-mail:851650827@qq.com.

About other authors:

Meili Liang,

Female, a native of Yantai in Shandong Province, lecturer, School of Management, Shandong University of Technology;

Qi Zhao,

student of Shandong University of Technology.

Fund Project:

One of the research results of Shandong University Humanities and Social Sciences Research Project "Research on Customer Segmentation and Marketing Innovation Based on Decision Rough Set" (Project No.: J12WF86). 
ential to the public. ${ }^{[2]}$ A promotional content full of bright spots will spread to the whole network in a very short time. Secondly, enterprises will no longer rely solely on the simple one-way information transmission such as television, newspapers, etc. when they propagate, and become more and more prominent in the form of communication. With the interaction between consumers and the openness and diversity of activities, consumers become more and more active and active. The attitudes and practices of advertisers in the face of advertisements have also changed. The application of new media technology has shortened the distance between enterprises and consumers, enabling consumers to understand commodities more deeply and quickly and establish with other consumers. One kind of connection (such as purchase evaluation of Taobao) greatly enhances the participation and initiative of consumers in advertising activities; on the other hand, the data flooding and the uneven content of information brought about by the new media age make consumers easily into a state of exhaustion, which makes it more difficult to attract consumers 'attention and trust.

\section{Disadvantages of Traditional Communica- tion Strategies in the New Media Age}

With the advent of the new media age, the disadvantages of Corporate Communication Strategies in the traditional media age have become increasingly apparent. Obviously, it is not wise for enterprises to stick to traditional communication strategies.

\subsection{Emphasizing Platform, Ignoring Consumer Feelings}

In the age of traditional media, in the process of formulating advertising strategies, enterprise marketers usually focus their attention on the specific quantitative indicators of media platform selection. This is a typical "media-oriented, audience-oriented" mode of thinking, which is easy to create a "media-based" mode of thinking, ${ }^{[3]}$ often ignoring the important factor of consumers. If once a sensation of CCTV Spring Festival Gala Spring Festival Evening Advertising Fee Event, many enterprises are competing for a high price in order to occupy a place in the Spring Festival Gala, the result will obviously not only increase costs, but also won the attention and recognition of consumers.

\subsection{Advertising Content Lays Stress on Product Characteristics, and It Is Hard to Attract Con- sumers with Rigidity and Emptiness}

In the age of traditional media, enterprises not only need to spend a lot of money to put advertisements on TV and radio platforms, but also need to hire professional advertising company personnel to plan advertisements for products. This often leads to the over-emphasis of advertising content on product characteristics, thus ignoring the concerns and attractions of consumers. The interests of advertisements are often based on the position of enterprises and content deviates. The actual situation of consumers makes it difficult to attract consumers 'attention and it is difficult to have emotional resonance with consumers, so the effect is not ideal.

\subsection{The Cost Is Too High and the Consumer's Ac- cessibility Is Low}

In the age of traditional media, taking advertising as an example, enterprises need to spend a lot of capital on selecting platforms and advertising production, especially on star endorsement and golden time programs of platforms. Only large enterprises with certain scale and financial strength can really make decent advertisements.

\subsection{The Poor Interaction Makes Consumer Feed- back Difficult to Reflect}

In the age of traditional media, most of the advertisements put by enterprises are made by advertising companies according to the image, product characteristics and marketing strategies of enterprises. Consumers play a very small role. After the advertisement is produced, the media put in are determined by the cost of advertising invested by enterprises. The interaction between enterprises and consumers is poor, and they cannot receive feedback from consumers and reflect it. In the process of communication, consumers 'feedback will influence the effect of advertising.

\section{The Change of Communication Elements in the New Media Age}

\subsection{Social Platforms Are Widely Used and Inter- active}

With the development of social platforms such as Weixin, Weibo and Short Video, a large number of netizens are gathered on social platforms. Social platforms undoubtedly become an important battlefield for enterprises to carry out product publicity and image building. With the wide application of social platforms, the main body of advertising is no longer the enterprise itself. Consumers not only rely on the one-sided words of corporate advertising to control their purchasing behavior, but also refer to the post-purchase evaluation of other consumers. The interac- 
tion between consumers and enterprises is enhanced, and the interaction between consumers and consumers is also greatly increased. ${ }^{[4]}$ For example, in Taobao, a large part of the factors that determine whether an ordinary consumer will buy are baby evaluation. Most people will first refer to the evaluation before deciding whether to buy Taobao.

\subsection{Consumers Have High Initiative and Play an Important Role in Communication}

In the new media era, many consumers are no longer satisfied with being simply promoted, but actively participate in the product chain. From the production of enterprises to the hands of the final consumers, consumers will take the initiative to participate in the process of understanding information. When consumers know a better product or see a very innovative advertising copy, they will forward propaganda through their own social platform; otherwise they will disclose bad products, which play a huge role in the process of enterprise information dissemination. For example, Xiao Hong Shu often has some cosmetic references, which are given by some consumers who have used the products, and the vast consumer groups will evaluate their attitudes towards the enterprise products accordingly.

\subsection{There Are Many Ways of Communication and the Content Is Crucial}

The importance of public relations has become increasingly prominent, and public relations planning are flourishing. Wechat public number push, H5, microblog, microfilm, flash shop and other forms emerge in endlessly, and even some enterprises have shifted the focus of communication from traditional television platforms to online social platforms. The way of production is no longer just a simple banner, propaganda or a huge cost of TV video advertising production. At the same time, a successful screen-brushing advertisement must have enough eye-catching content in addition to its excellent production. For example, the packaging bottle of Nongfu Mountain Spring is its unique propaganda way, which is frequently hot search; Netease Cloud Music also opens its own market by its popular comments from netizens, whose content is from the vast APP application groups, which easily arouses the resonance of consumers.

\subsection{The Main Body of Communication Is Not Limited to Enterprises}

Anyone can turn into a dominant communicator, especially some senior executives and social leaders. Celebrity Effect Gathers Fan Power, ${ }^{[5]}$ they can successfully transform themselves into the main communicator of advertising information. Through its strong language persuasion and appeal in communication, it can deeply absorb the audience and stimulate their desire to buy related products. For example, Chen Ou of Jumeiyoupin has accumulated super popularity for himself by virtue of "I Speak for myself”, which has far-reaching influence.

\section{Case Analysis of Enterprises}

\subsection{Case Analysis of Jiang Xiaobai}

Jiang Xiaobai is a brand of Chongqing Jiangxiaobai Liquor Industry Co., Ltd. devoted to the new taste of traditional Chongqing sorghum liquor. With the brand concept of "I am Jiangxiaobai, life is simple", adhere to the anti-luxury product concept of "simple packaging, refined wine", adhere to the brand spirit of "simple, pure, independent", and continue to build "I am Jiangxiaobai" brand IP and use. Interactive communication between households will continue to promote the fashion and market internationalization of traditional Chinese fine wine brands.

"Simple and pure" is not only the taste characteristics of Jiang Xiaobai, but also the attitude of life advocated by Jiang Xiaobai. Jiang Xiaobai advocates that young people should face up to their emotions, not avoid, not fear and be themselves. "I am Jiang Xiaobai, life is very simple" brand advocacy has penetrated into all aspects of modern youth life in the 21 st century, and has multiplied such articles as "face-to-face wine appointment", "good friend's wine party", "I have a bottle of wine, something to say to you", "another me in the world", "See Meng World Youth Art Exhibition", "Jiang Xiaobai Just Battle International Street Dance Competition" and so on. With the fermentation of time, Jiang Xiaobai's "simple and pure" brand image has evolved into a self-communicating cultural IP. More and more people are willing to express themselves by "Jiang Xiaobai". For this complex world, perhaps everyone is Jiang Xiaobai.

In the new media age, enterprises are required to achieve "customer-centered" at a higher level. It is not simply to listen to consumer needs and solve consumer problems. More importantly, it is important to make use of new media technologies such as the Internet to enable consumers to participate in every link of the business chain.

2017 is the 20th anniversary of the establishment of Chongqing municipality directly under the Central Government. Jiang Xiaobai and Zhang Yanming jointly created a city MV "Hello, Chongqing". The short MV tells the stories of six pairs of ordinary people in this city, including the feelings of men and women, reality and ideals, and 
the feelings of returning home... Seemingly ordinary, but are our lives, let people feel thousands of. From this point of view, a series of emotional Chongqing theme posters and theme wine packaging were launched.

The communication strategy for Jiang Xiaobai's success includes three main points:

(1) Give Brand Images to Target Consumer Groups

Unlike the traditional white wine company, Jiang Xiaobai designed his own specific image: slightly long black hair, compared with Han Fan's hairstyle, always wearing a pair of black-rimmed glasses, standard comic public face. Daily dress is white T-shirt with grey scarf; the coat is British style long black windbreaker, the lower body with dark grey jeans and brown casual shoes. If you want to match a real person, it's probably Gu Xiaobai, played by Sun Honglei in The Gang of Men, which is the origin of Jiang Xiaobai's original inspiration.

Jiang Xiaobai also contacts consumers with the image of Jiang Xiaobai as the first person on his micro-blog and Weixin account. This approach not only closes the gap with consumers, but also reduces the barrier. The most important thing is that the image positioning fits the product positioning very well, which makes a deep impression on consumers and easily leads to the co-existence of consumers in the target market.

Three squirrels are also in place in terms of brand representations. It draws closer to the relationship with consumers through personified communication, which adds interest to the communication process. ${ }^{[6]}$

(2) Make Full Use of the Power of New Media Platforms Commonly Used By Target Customer Groups

Jiang Xiaobai hardly ever advertises in the mainstream media. Apart from subway advertisements, Jiang Xiaobai basically has no traditional marketing methods, and the most used is free social media.

For the use of highly interactive social media, Jiang Xiaobai's micro-blog marketing shows several distinct characteristics: first, good at text implantation, will be interesting topics and Jiang Xiaobai's products linked. Secondly, corresponding to their own brand image, the operation of micro-blog is completely personified. Speak up when all the hot events, show your attitude; finally, use micro-blog interaction as an online tool to organize offline activities, and interact with online to enhance the stickiness of fans.

In addition to Weibo, Weixin has also become one of Jiang Xiaobai's communication channels. Compared with Weibo, Weixin has a higher degree of privacy. Jiang Xiaobai's director of public relations, Shu Bo, said that besides Weixin's public account, Jiang Xiaobai also operates a private account of Xiaobai, which is maintained by a ded- icated person and does not belong to any of Jiang Xiaobai's employees. "Because some fans will tell little white brother some privacy, so this account is not open except for the person responsible for the operation, including I do not know." Shu Bo said.

With the above interactive platform, Jiang Xiaobai successfully accumulated a large number of fans for himself without any effort. Every update of the text will basically cause a lot of forwarding and attention.

(3) Oxygen Dioxide Marketing Model Based on Public Relations Advertising Communication

Jiang Xiaobai locates in the young people after 80 and 90. Except for the subway advertisements, all of them adopt the $\mathrm{O} 2 \mathrm{O}$ marketing mode based on the communication of public relations advertisements. It is this innovation that makes Jiang Xiaobai rise like a black horse in the liquor industry of China.

Jiang Xiaobai has fully grasped the thinking of young Internet users in the age of new media, and realized "customer-centered" at a higher level. Particularly emphasis on user experience, pay attention to communication with consumers, so that users in their text into their daily lives, so that users can truly perceive and exceed users'psychological expectations, every user will feel after seeing Jiang Xiaobai's advertising text - "This is me!" Everyone has read a copy.

The real feeling of every person who has read the text is the effect that Jiang Xiaobai is committed to creating, so as to maximize the value of users, and also succeeded in winning the world by "Dian Si".

\subsection{Case Analysis of Netease Cloud}

Netease Cloud Music is a music product developed by Netease, with song lists, DJ programs, social, geographical location as the core elements, the main role of discovery and sharing. Netease Cloud is a dark horse in music APP. In the new media age, it quickly occupied the market relying on its music review and subway advertising.

In March 2017, Netease Cloud Music first creatively commented on those deeply touching songs, which were printed on Hangzhou Metro Line 1 and Jiangling Road Metro Station. "Those who cry over their meals can go on." "How many people love silently in the name of friends." These copies, screened out from 400 million comments, hit the hearts of the people, connected with the "struggle fatigue and loneliness" pervasive in the subway, and quickly detonated the spread offline. In just a few days, Netease Cloud Music Review Special Line received more than 2,000 Wechat public reports, with a total reading of more than 10 million; Baidu Index increased by $80 \%$; Wechat Index doubled 216 times, reaching a peak of 
13 million.

Netease Cloud communication strategies have the following two points are particularly worth learning.

(1) Actively Use Perceptual Appeal to Make Products That Resonate With Users

Whether it's music review, accurate personalized recommendation, and friend dynamic functions, NetEase is looking for a way to create a brand image that "moderately alleviates loneliness while maintaining personal independence". The subway advertising campaign, carefully using 85 selected comments, disseminated on Hangzhou Metro Line 1, is a way of emotional resonance to help users alleviate loneliness and heal their hearts. In the process of communication, enterprises should not only rely on rational appeal, but also actively use perceptual appeal. Use emotions to influence the audience's attitudes towards products and enterprises. ${ }^{[7]}$

(2) Use UGC Skillfully to Influence Users

First of all, in the scenario of Internet accessing, Yiyun has chosen the subway which has a large flow of people and is ubiquitous. In such a closed space, users'attention is often easy to concentrate, and emotional infections between people are easier. Secondly, in terms of advertising content, Netease Cloud Metro Advertising 2.0 is a typical brand of UGC communication. Through the unique user music reviews of Netease Cloud, take it from users and use it for users, a large number of high-quality UGC content will continue to flow, ensuring the durability and influence of brand characteristics. In this way, Netease Cloud will present the story behind each user's music review to more users, which makes it easier to transfer and resonate between emotions.

\section{Suggestions on Corporate Communication Strategies in the New Media Age}

Through the above two cases, we can see that the communication strategies of enterprises in the new media age must be adjusted according to the changes of the times, fully considering consumers' consumption psychology and needs, choosing the platform that consumers are easy to contact, and at the same time, using the power of consumers and social public opinion, making the positive energy of communication strategies fully displayed, in order to maximize the presentation of communication effect and achieve twice the result with half the effort. Function.

(1) Accurately Locate Consumers and Select Appropriate Platforms

Firstly, Enterprises must conduct in-depth and thorough analysis of their target consumer groups. ${ }^{[8]}$ In addition to the basic information such as gender, age and consump- tion level, they should subdivide the consumer groups into precise market segments, and pay more attention to the media preferences, hobbies and hotspots of the target consumer groups. Even grasp the target group's Internet habits, targeted advertising and other information. ${ }^{[9]}$

After precise positioning, we should choose the media that the target consumers prefer to contact. In choosing the platform, we should optimize the media mix in addition to suiting the preferences of the consumer groups, so as to cover the consumer groups to the greatest extent and make comprehensive use of various traditional media and new media, instead of putting eggs in a basket to give full play to the cost advantages of new media.

(2) Content Is the Key to Winning

If enterprises want to make breakthroughs in communication performance, they must grasp the key link in the operation of new media, that is, the attention of communication content. The greatest feature of the new media age is "content is king". As long as the content has enough attraction and innovation, or is valuable to the audience, the audience will help enterprises continue to spread, and the audience will become a new level of disseminators. This dissemination effect is exponential growth, that is, explosive and viral dissemination effect. ${ }^{[10]}$

First, the good content must be the content that readers like or value.. Therefore besides introducing the characteristics of products or corporate image, the content also needs to know the reading tendency of its target consumer groups; secondly, the good content mostly combines the current real-time hot spots, can make full use of the festival atmosphere, social hot spots and so on to increase attention for its dissemination; finally, the good content is also new. Rong, uniform advertising and public relations activities cannot withstand the impact of big data in the new media age. They are instantaneous and cannot catch the eyes of consumers successfully. Therefore, innovations must be added to the content to give consumers a fresh feeling.

(3) Creating New Forms and Drawing on the Power of Public Opinion

Enterprises in the new media age, in addition to coping with the increasingly complex and diversified consumer demand, but also to grasp the characteristics of various new media and use methods, to give full play to the power of the media, in order to achieve twice the result with half the effort, or even better.

Netease Cloud has made use of the subway as a medium, but has not been stereotyped to innovate its form, naturally succeeded in attracting the attention of the vast number of netizens, with a high degree of attention. In this way, its audience is not only the passengers who take 
the subway, but also spread rapidly to the whole Internet world with the various forwarding of netizens, which can be said to be "free advertising", and the effect is far beyond the reach of a subway advertisement. The planning of public relations activities can be used for reference.

(4) Developing Communication Strategies Centering on Consumers

In the new media age, the main body of information dissemination is not only enterprises, but also consumer groups which have become an important force of information dissemination. The two-way communication between enterprises and consumers, consumers and consumers is becoming more and more convenient. "Retribalization" makes it easier to communicate within tribes. ${ }^{[1]]} \mathrm{New}$ marketing methods such as word-of-mouth marketing, experience marketing and fan marketing emerge in endlessly ${ }^{[12]}$, especially the prevalence of integrated marketing communication, which requires enterprises to pay attention to the role of consumers and formulate communication strategies centered on consumers.

\section{Conclusion}

In a word, when formulating communication strategies, enterprises should conform to the target consumer groups, choose the appropriate media platform according to their own product characteristics, innovate the production methods of communication strategies, increase creativity for content, attach importance to user experience and fan marketing, in order to arouse the resonance of consumers, so as to maximize the communication effect. At the same time, it should be noted that there are many defects in the new media communication, including the low credibility of the content of communication, the serious lack of legal protection of consumers' rights and interests, and so on. Therefore, in the process of communication, enterprises should abide by market rules; actively safeguard the rights and interests of consumers, honest communication. Only in this way can they gain the recognition and support of consumers and establish a good brand image in the minds of consumers.

\section{References}

[1] Lu Wei, Fangzhou Ding. On the Transformation of Communication Research in the New Media Age[J]. Journal of Zhejiang University (Humanities and Social Sciences Edition), 2013(04).

[2] Junwen Wang. Research on Enterprise Marketing Strategies in the New Media Age[J]. Modern marketing (Late version), 2016(03).

[3] Shuangmei Li, Yu Li, Strategies for Selecting Enterprise Advertising Media Based on Focus Communication[J]. Jiangsu Commerce, 2008(01).

[4] Shu Yongping. Realization of Interactive Advertising Communication[J]. International Press, 2004(05).

[5] Wanwan Yang, Shangping Ma, Research on the Transformation of Brand Communication Model Based on Self-Media[J]. Jiangsu Business Theory, 2018(01).

[6] Shaoru Hu. Research on New Media Marketing Strategies of E-commerce Enterprises Based on Internet Thinking[D]. Guangdong University of Technology, 2017(10).

[7] Zheng Zhang, Yuan Liu, Xu Chen. Mobile Media Advertising Strategy Based on Persuasion Model[J]. News world, 2011(12).

[8] Liuyan Hong, Lincheng Jin. New Media Visual Marketing Strategies for Traditional Industry Enterprises[J]. Operation and Management, 2017(05).

[9] Yahong Lin. On the Publishing Strategy of Online Advertising[J]. Journal of Ningbo Radio and Television University, 2005(12).

[10] Li Rao. Yong Wang, Analysis of Network Marketing in the New Media Age[J]. China Business and Trade, 2015(03).

[11] Jixuan Liu. Marketing Change in the New Media Age[J]. Television Research, 2012(02).

[12] Gang Chen. An Analysis of Marketing Communication in the New Media Age[J]. International Press, 2007(09). 